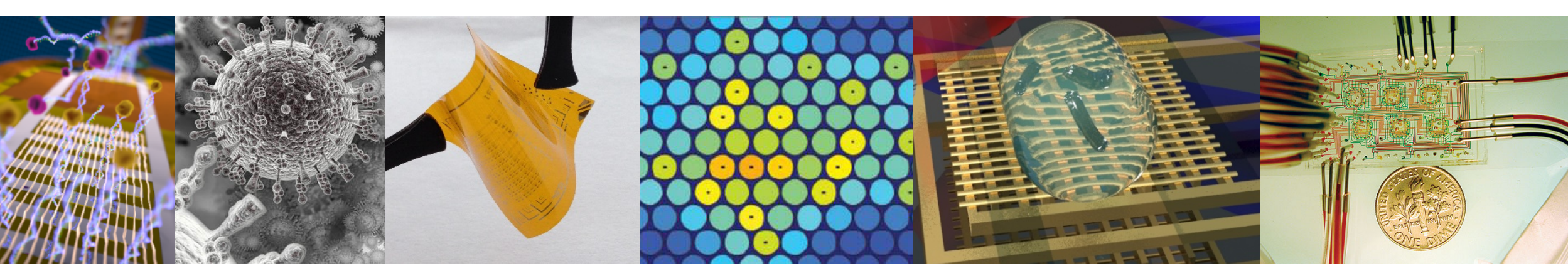

\title{
Nanoscopic biosensors in microfluidics
}

\section{High Potential Program supported by}

Institute of Radiopharmaceutical Cancer Research

and
Larysa Baraban HZDR 


\section{Dresden: Baroque and Hightech}

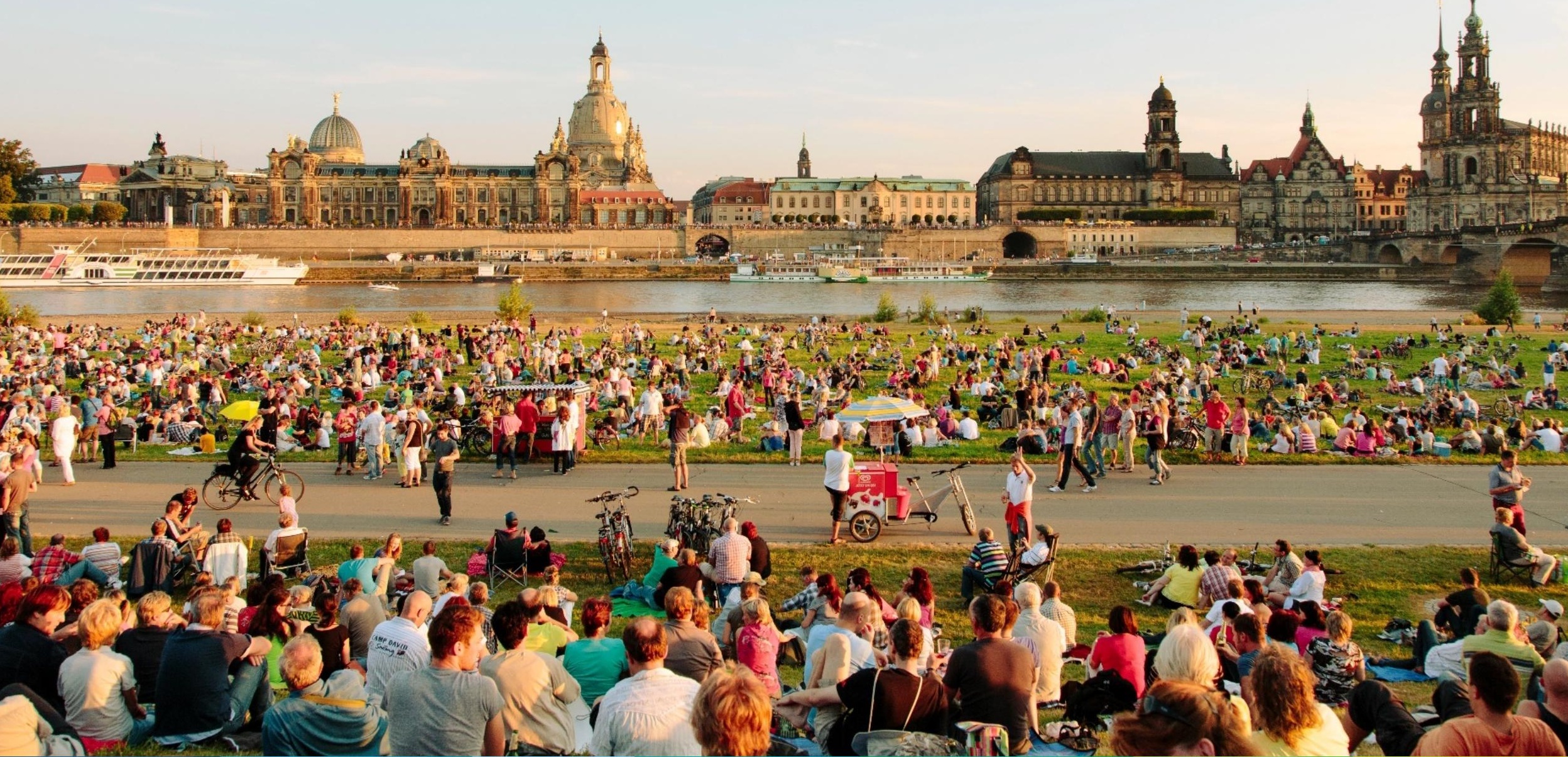


New approaches for an early detection and therapy

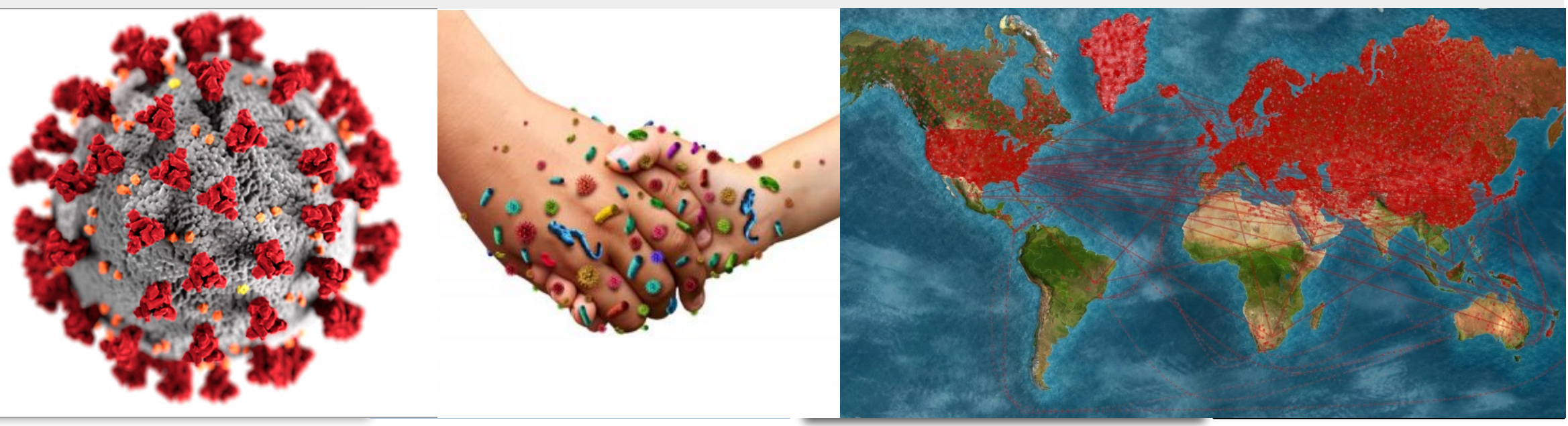

Challenge: low concentration of e.g. cancer cells circulating in the human blood; fast spreading diseases; time consuming clinical viral cell culture or antibody staining; global spreading of the microbes drug resistance 


\section{State of the art solutions available at the market}
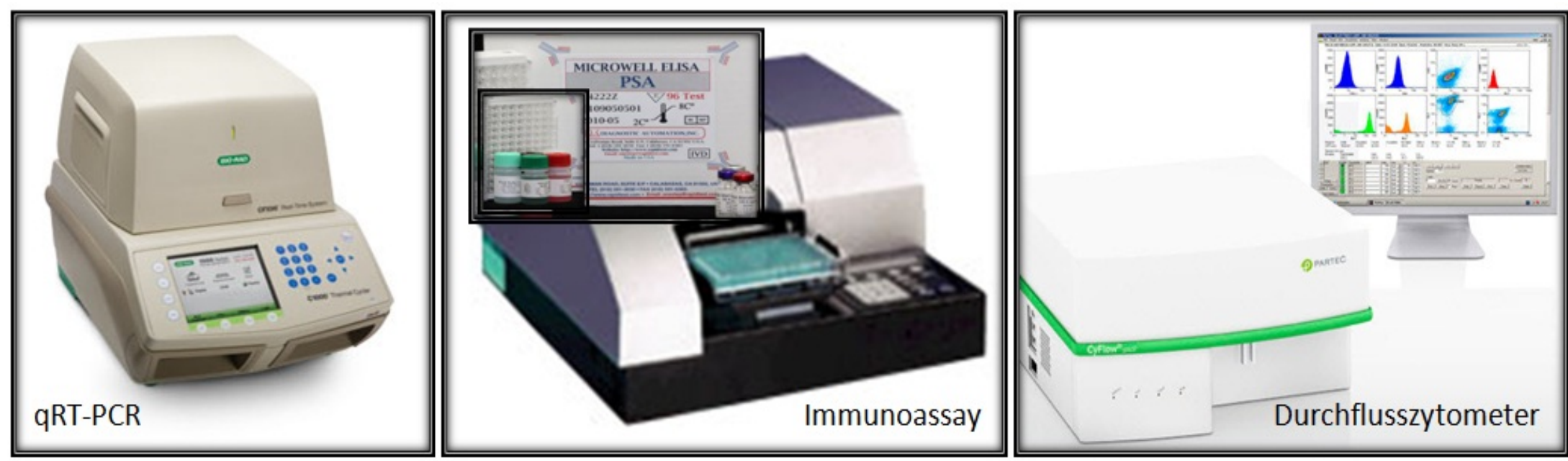

- Optical detection concepts are widely used

- Devices are bulky and relatively expensive

- New detection technologies are needed: miniaturized and cost efficient 


\section{Towards novel format of the molecular testing}

U.K. point of care diagnostics/testing market size, by product, 2014 - 2025 (\$ Million)

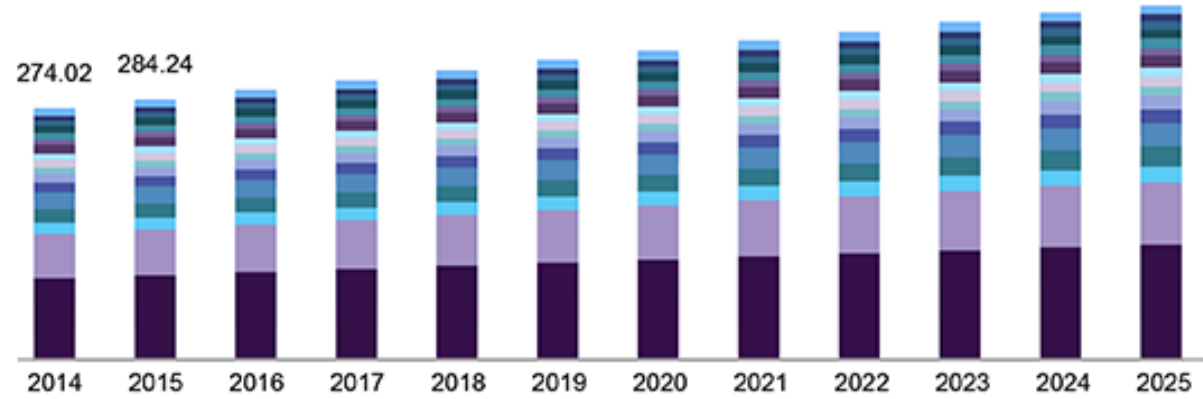

a Glucose Testing = Hb1Ac Testing ㅂ. Coagulation = Fertility = Infectious Diseases

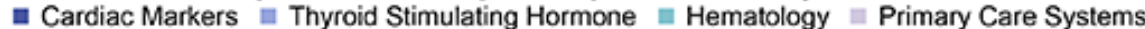
Decentralized Clinical Chemistry a Feces a Lipid Testing a Cancer Marker

a Blood Gas/Electrolytes a Ambulatory Chemistry a Drug Abuse Testing ㅂ. Urinalysis Source: mww.grandviewresearch.com

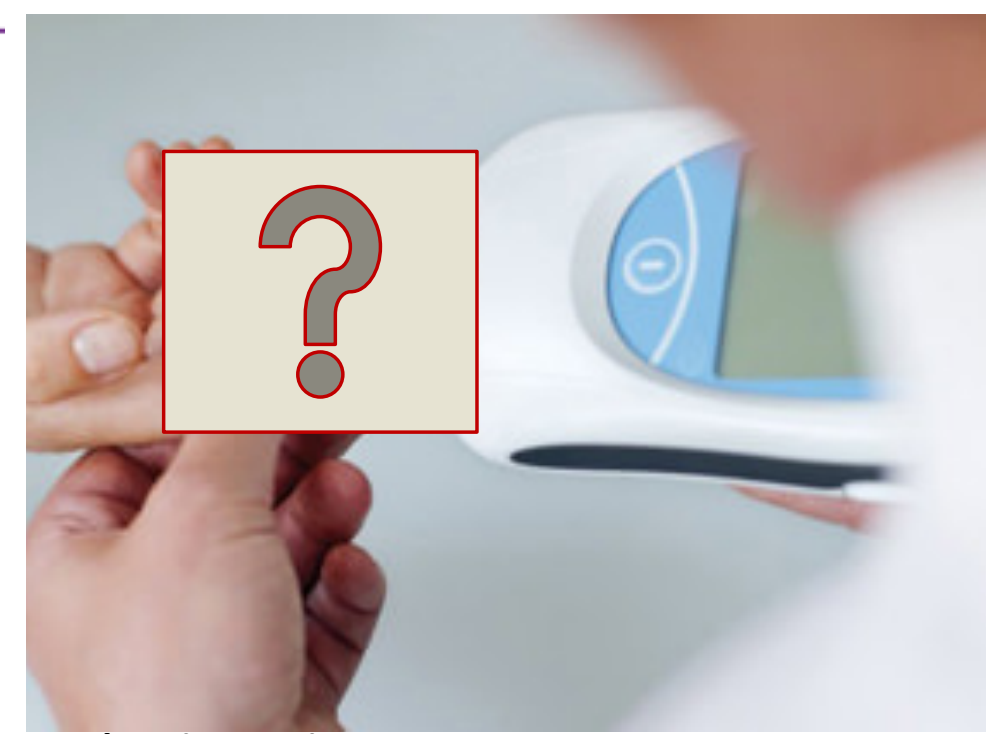

Roche Diagnostics 
New technologies for future diagnostics

Nano and organic materials Bio-integrated electronics

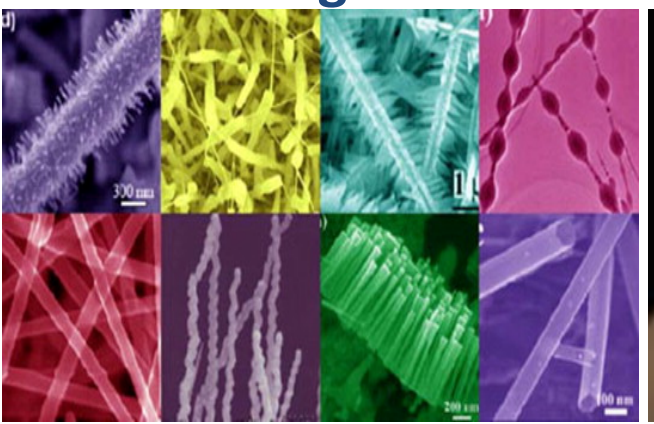

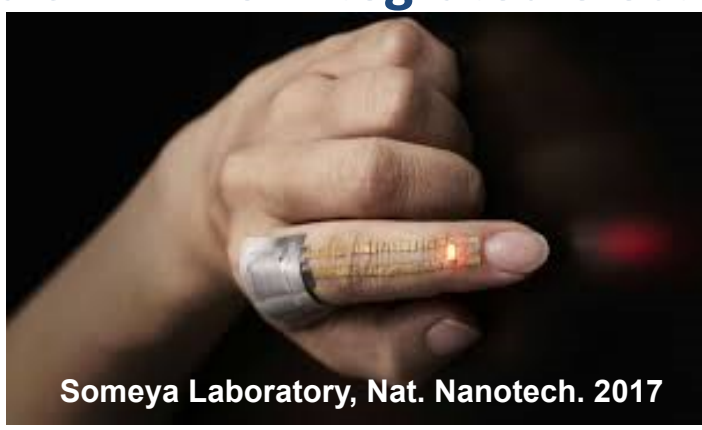

Microfluidics
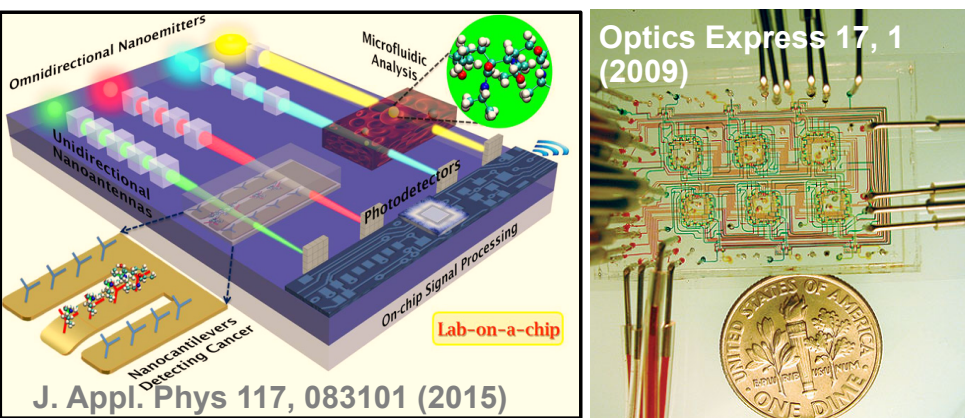
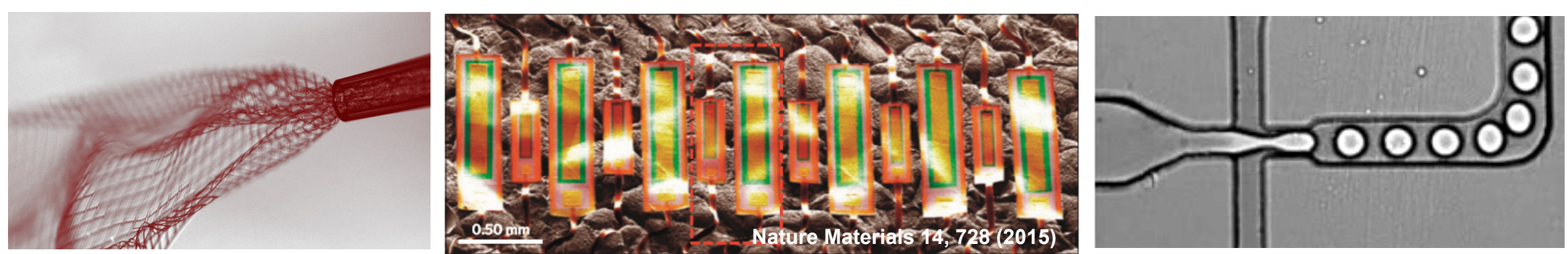

$\rightarrow$ High sensitivity

$\rightarrow$ Quick analysis

$\rightarrow$ Portability

$\rightarrow$ Cost efficiency 


\section{Why nanosensor?}

\section{Sensitivity issue \\ $\Delta \mathrm{G} / \Delta \mathrm{N}=$ ?}
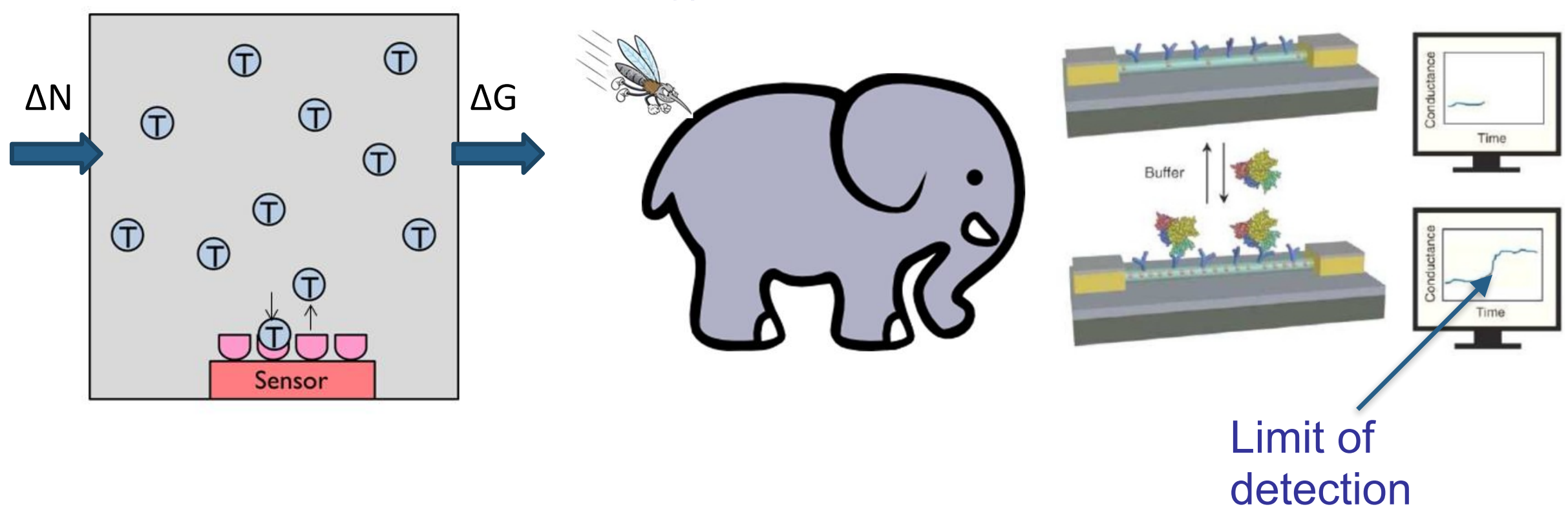

Need for miniaturized sensors 


\section{Point of care from the nanoscale}

\section{Bioelectronics}

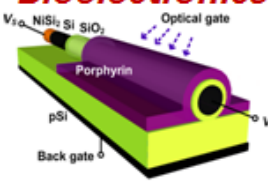

Nano westan

Research

Bacteria

Metabolism

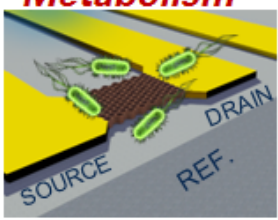

Droplets

\& FET sensor

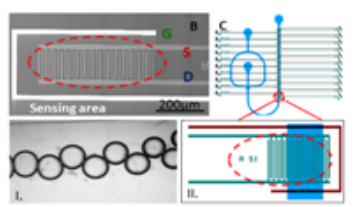

M. M. Sanchez et al., Nano Letters, 16(7), (2016).

D. Karnaush., et al. Adv. Health. Mater., 4, (2015)

J. Schuett et al., Nano Letters, 16(8), (2016).

E. Baek et al., Nano Letters, 17(11) (2017).
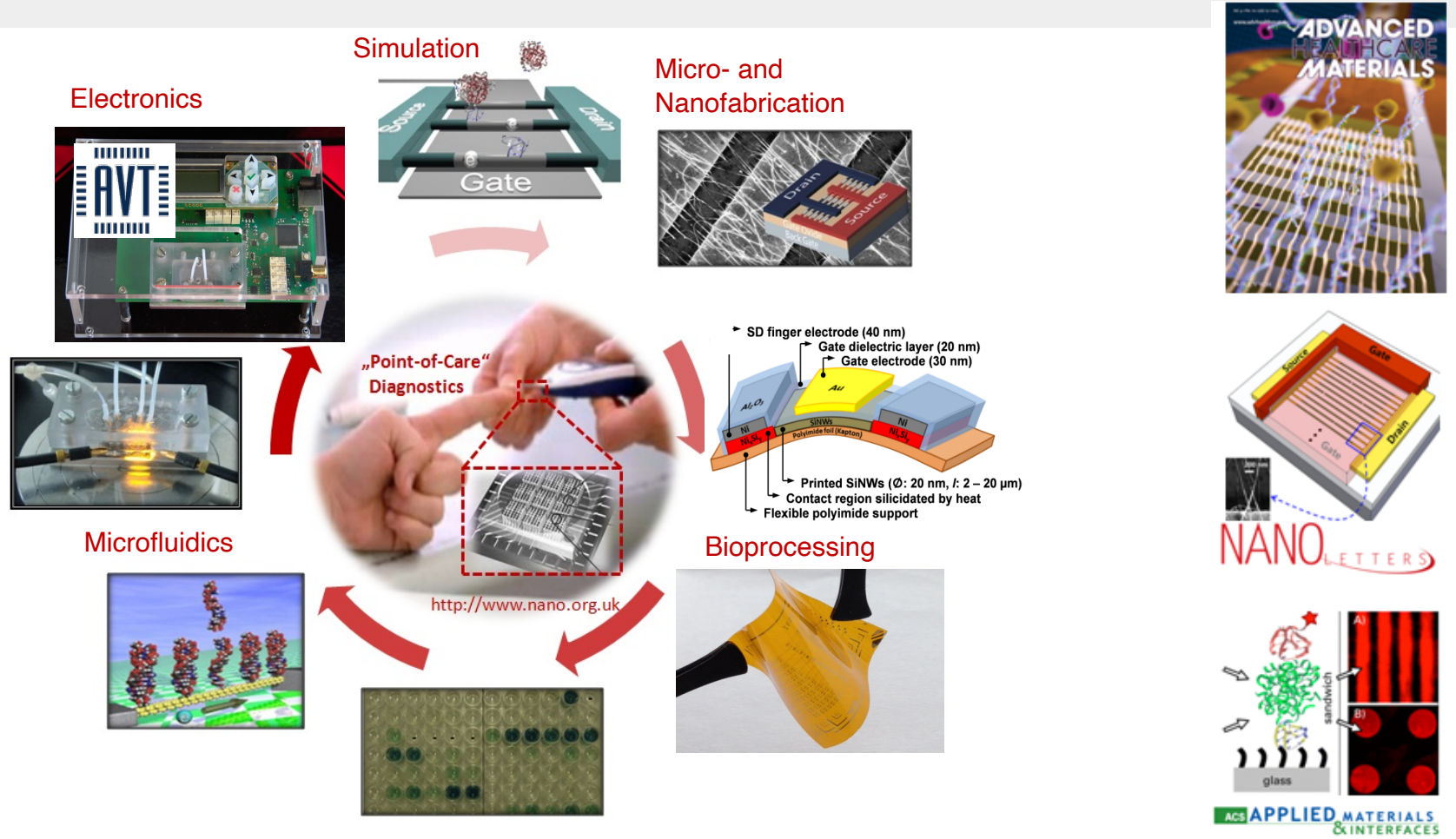

E. Baek at al., Nature Electronics, accepted.

P. Zhang et al., Small, 15 (23) (2019).

L. Baraban et al., Advanced Science, 6 (15) (2019).

S.W. Park et al., Angew. Chem. Int. Ed., (2020)

J. Schütt et al., Nano Letters, 20(9), 6572(2020). F. Zoergiebel et al., Nano Research, 7(2), (2014).

T. Huang at al., Adv. Func. Mater., accepted. 


\section{Outline}

Development of new nanodevices and tools for lab on chip systems

$\checkmark$ SiNW FET sensors and systems

$\checkmark$ Gold nanowires based impedance sensors systems for blood analysis

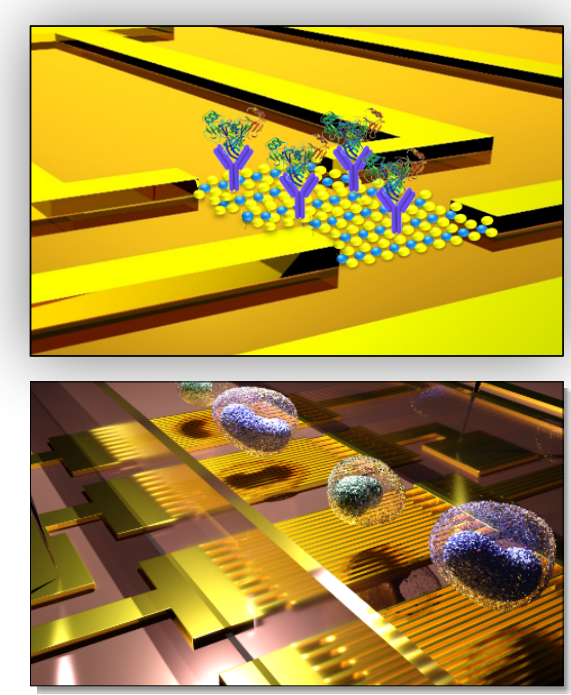




\section{Si-NW FET sensors and systems for molecular detection}

J. Schuett et al., Nano Letters, 16(8), (2016).

E. Baek et al., Nano Letters, 17(11) (2017).

D. Karnaushenko, et al. Adv. Health. Mater., 4, (2015)

D. Y. Jeon, et al. Nano Lett., 15(7), (2015)

E. Baek, et al., Nano Research , 8(4), (2015).

S. Pregl, et al., Nano Research , 6(6), (2013).

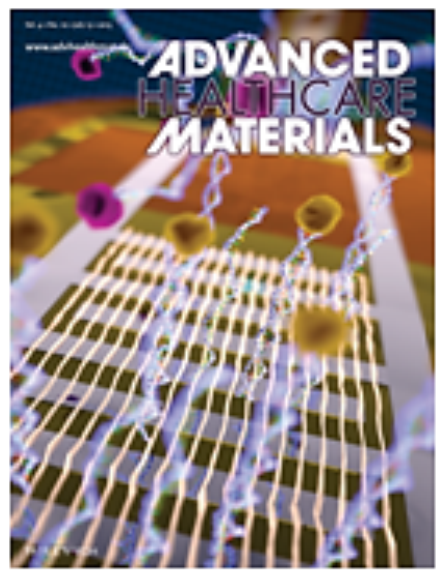




\section{Nanowire devices - label free devices}

Potentiometric device: transforms the charge into the current

FET that is used to track analogue signal change

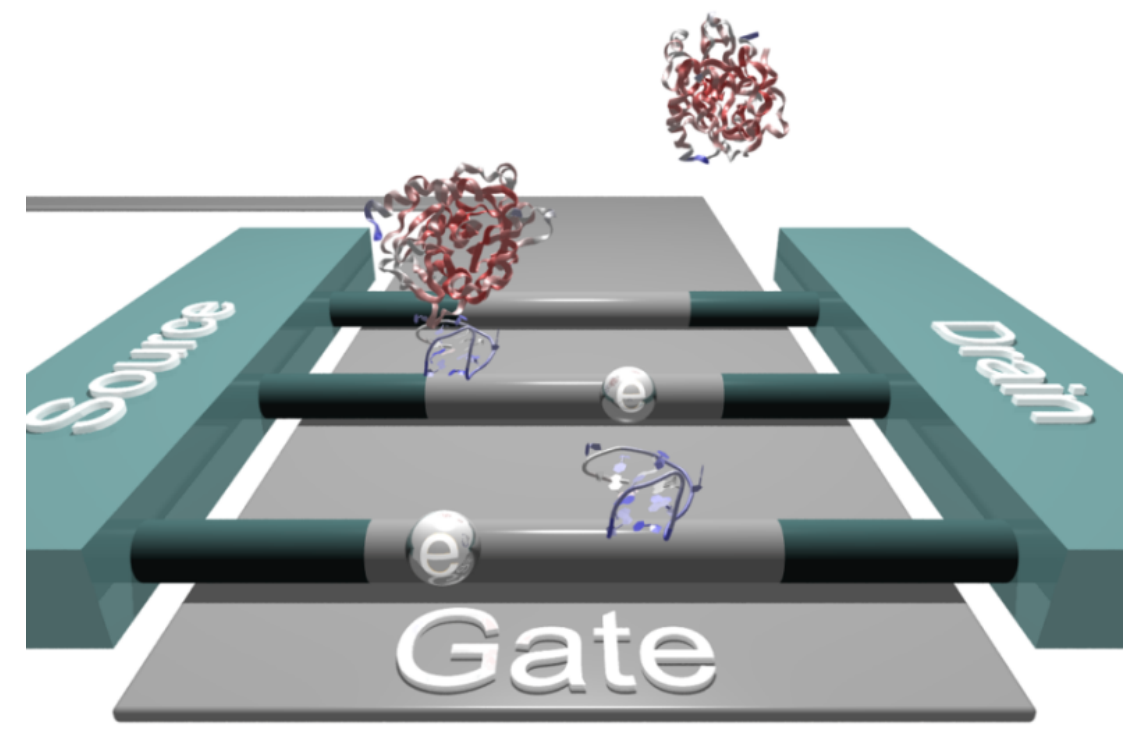

$\checkmark$ Higher surface to volume ratio

$\checkmark$ Higher current modulation for the same active sensor area 


\section{How does it operate?}

\section{Concept of the sensor device:}

(1) Silicon nanowires assembled as field effect transistors (FETs)

(2) Surface of the NWs play crucial role in the sensing the microenvironment

(3) Changes of the surface charges: gate effect

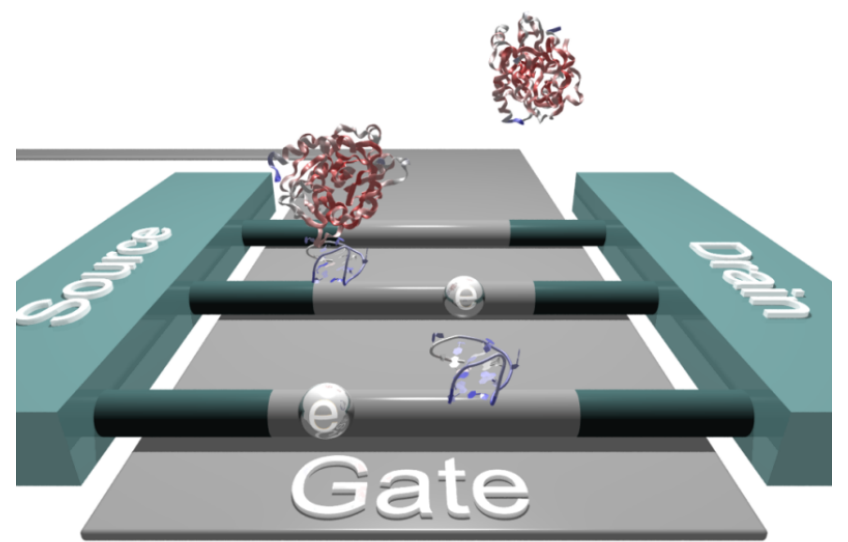

$\checkmark$ Higher surface to volume ratio

$\checkmark$ Higher current modulation for the same active sensor area

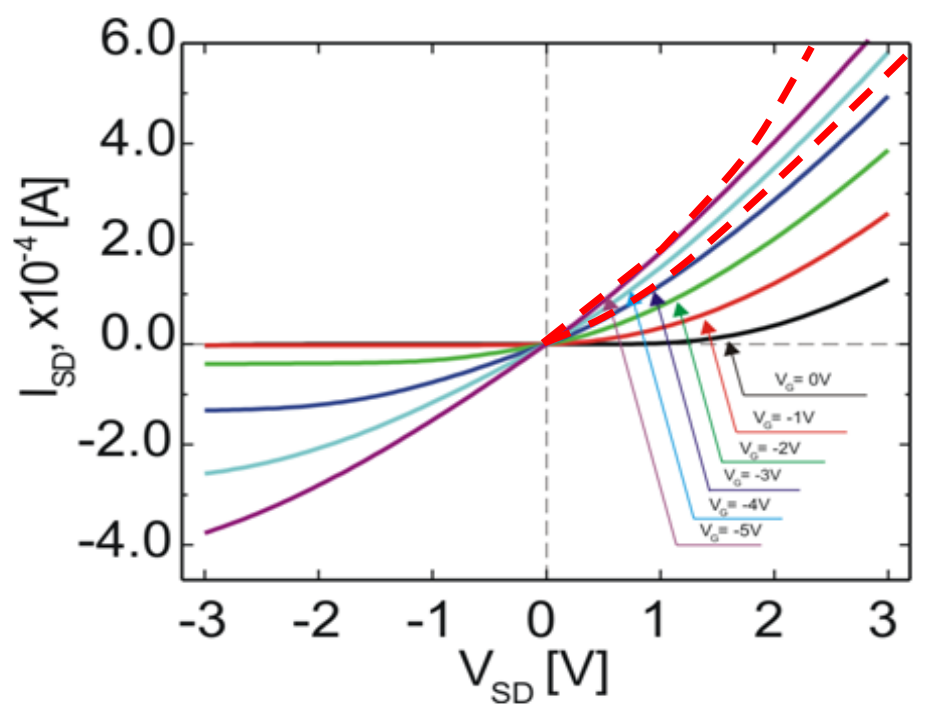




\section{Si NW devices for sensor platform}
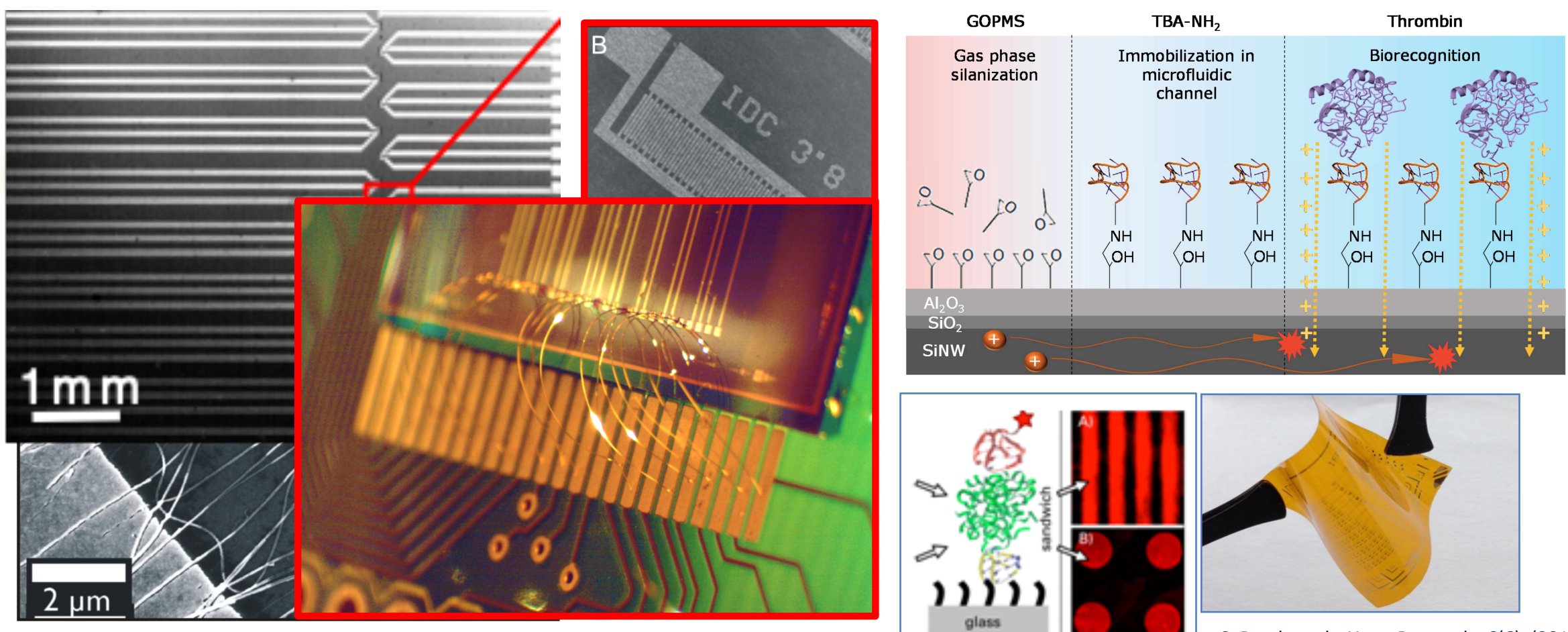

E. Baek, et al., Nano Research , 8(4), (2015).

F. Zoergiebel et al., Nano Research , 7(2), (2014). 


\section{Clinical applications}


Real time monitoring of stress biomarkers: human testing
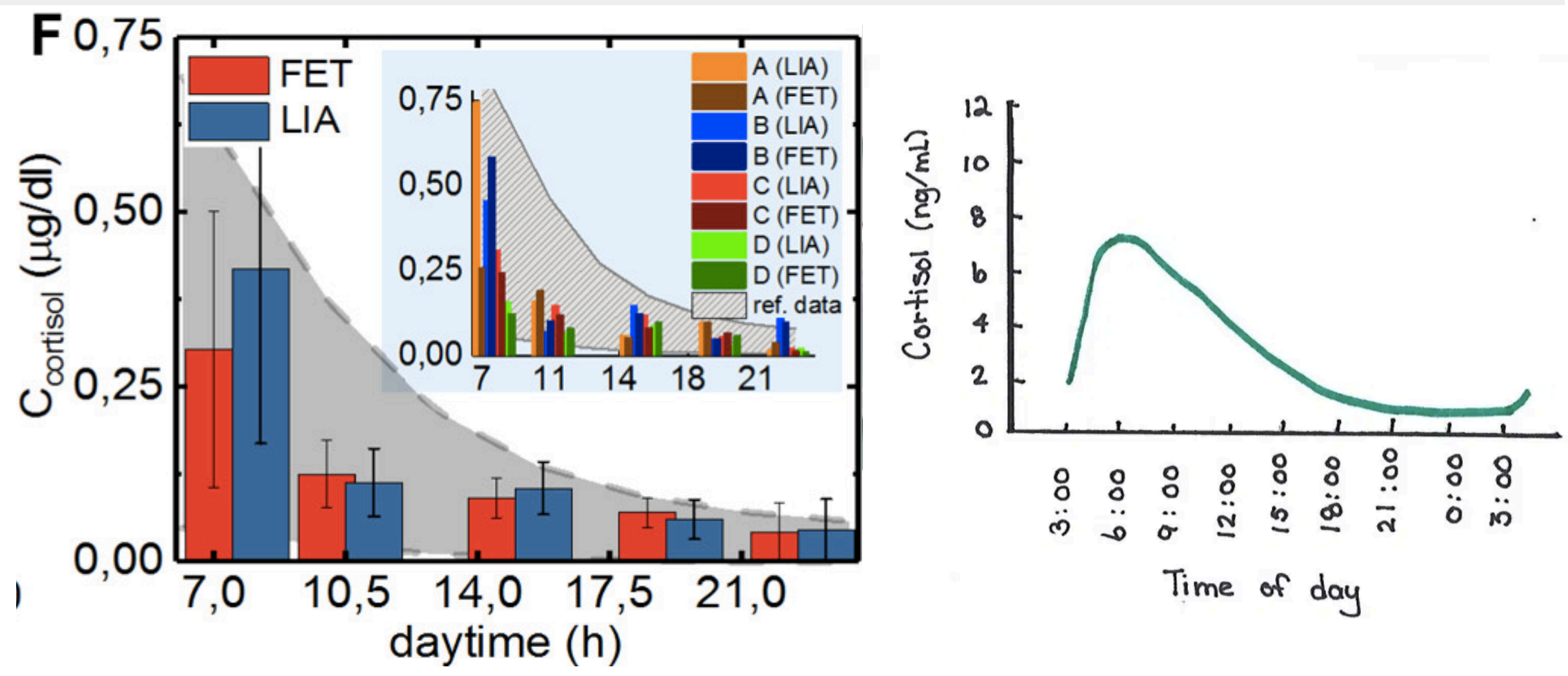

Cooperation: Clemens Kirschbaum, Biopsychology 


\section{Immunotherapy monitoring}

\section{CAR T-cell Therapy} patient to get $T$ cells

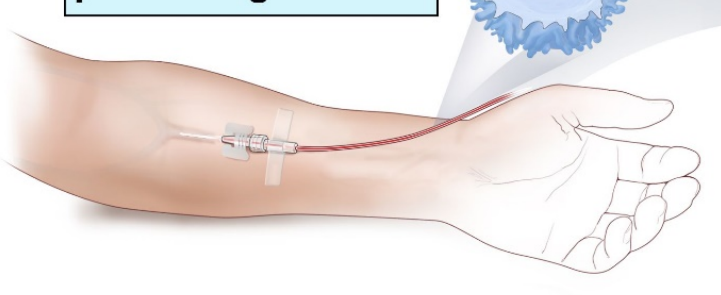

CAR T cells bind to cancer

cells and kill them

Cancer cell

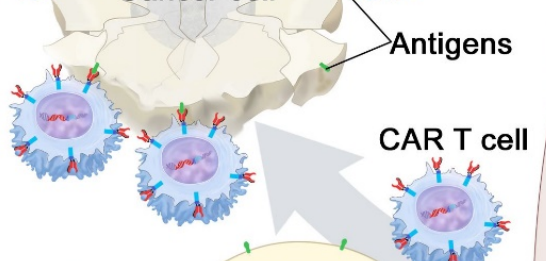

Cancer cell

\section{Remove blood from}

T cell

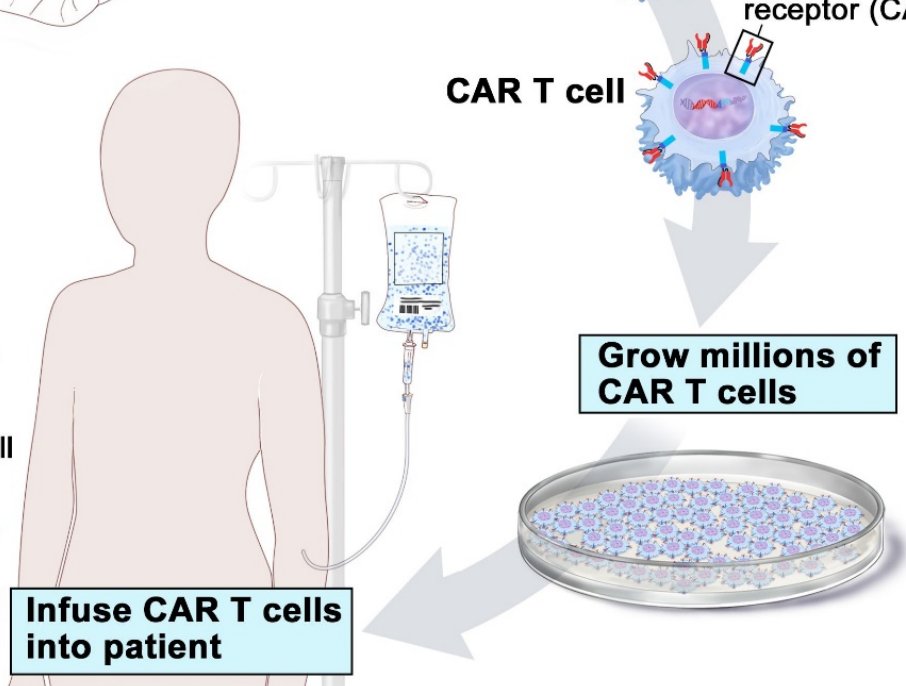

Insert gene for CAR SIDUDOUN
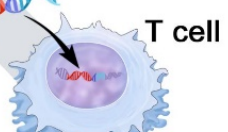

\section{Make CAR T cells in the lab}

Chimeric antigen receptor (CAR)

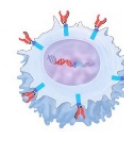

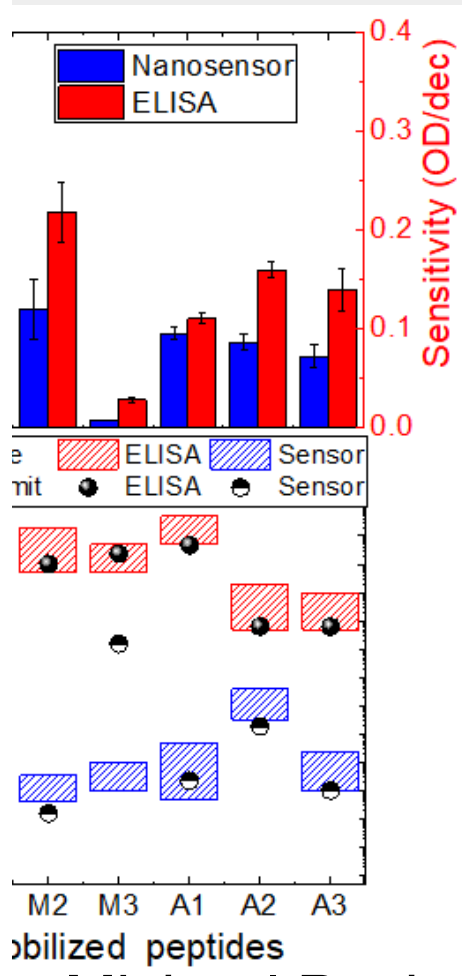

sbilized peptides

I: Michael Bachmann (HZDR),

Ahn Trang Nguyen-Le et al., submitted 
Metal nanowire based impedance sensors

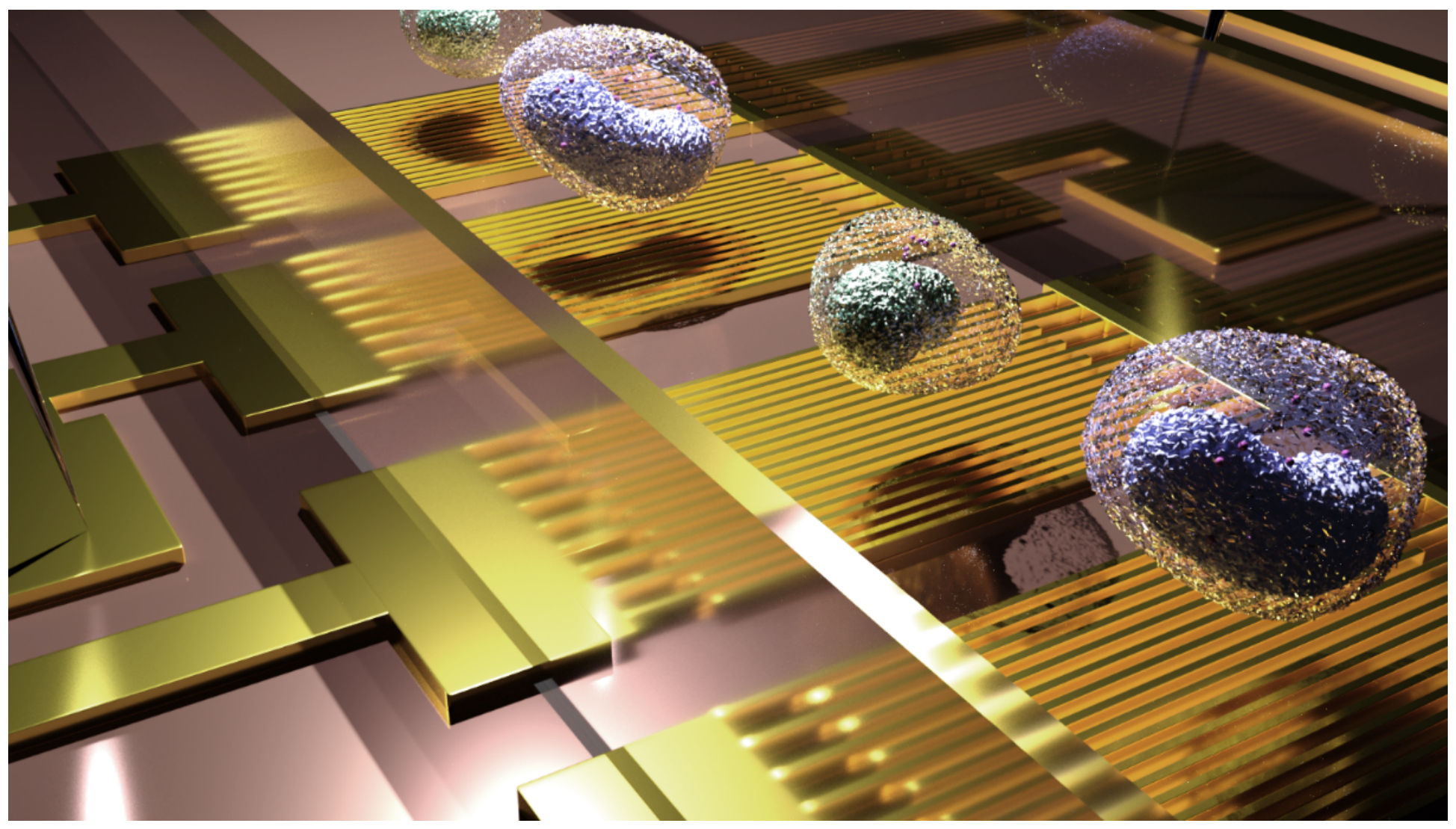




\section{Metal nanowires impedance based system}

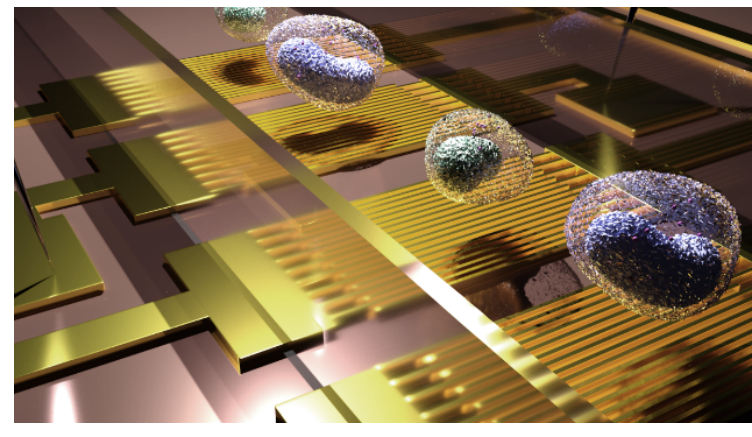

Impedance spectroscopy

Scan of the frequencies to detect analyte

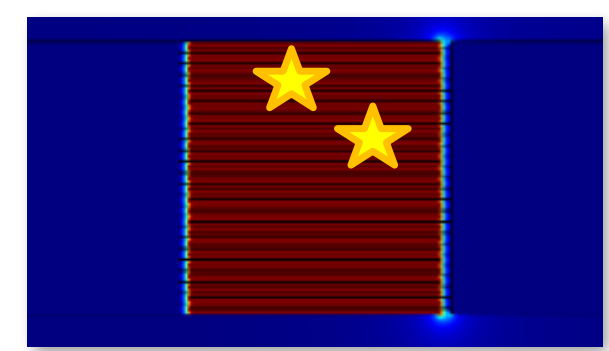

Static mode!

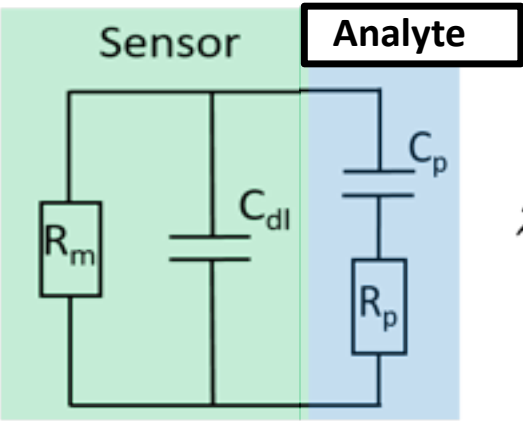

$\hat{z}(j \omega)=R+\frac{1}{j \omega C}+j \omega L$

Impedance cytometry

Dynamic mode!

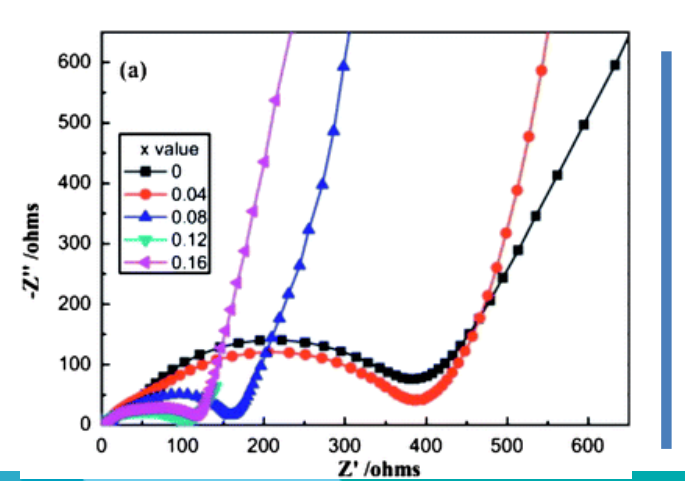

Constant frequency in time domain

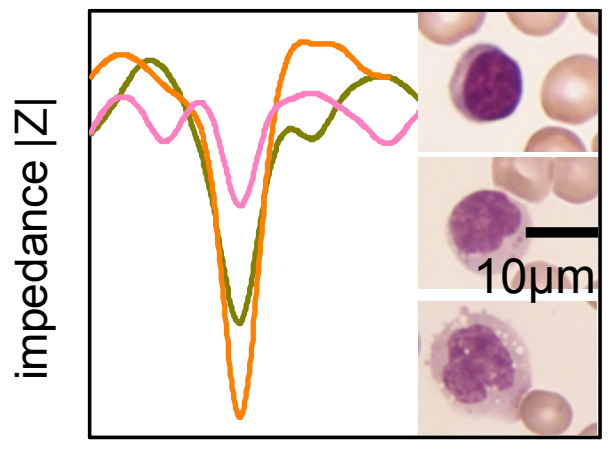

Monocytes

T-cells

NK-cells 


\section{Summary and Outlook}

- Electronic nanobiosensors

○ Microfluidic analysis

- Towards complex nanosystems for analysis of the biological systems

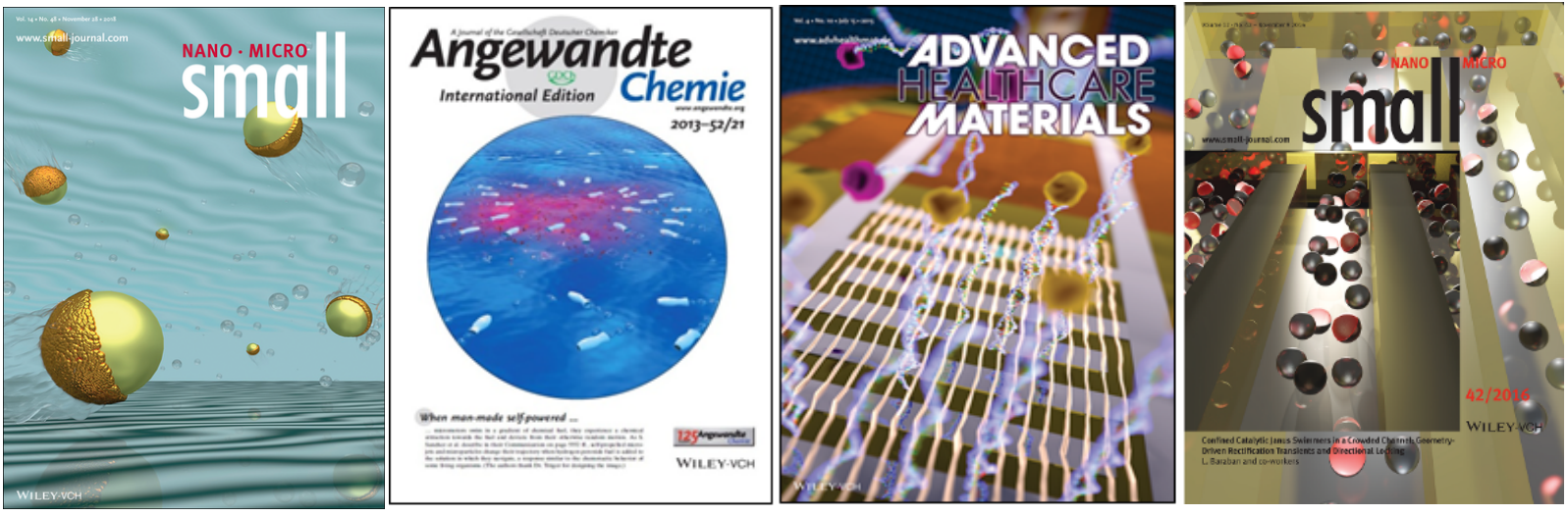




\section{Thanks}

\section{Thank to all collaborators:}

Walter M. Weber, TU Wien

Thomas Mikolajick, TU Dresden

Oliver G. Schmidt , Leibniz IFW

Gianaurelio Cuniberti, TU Dresden

Denys Makarov, HZDR

Arben Merkoci, Barcelona

Samuel Sanchez, Barcelona
Martin Bonhäuser, Uni Klinik Dresden (Hematooncology)

Michael Bachmann, HZDR

Peter Spieth, Uni Klinik Dresden (Anesthesiology)

Juergen Weitz, Uni Klinik Dresden (Surgery)

Clemens Kirschbaum, TU Dresden, (Biology)

Arjan de Visser, Wageningen

Joost de Graph, Utrecht 
Thanks to the group

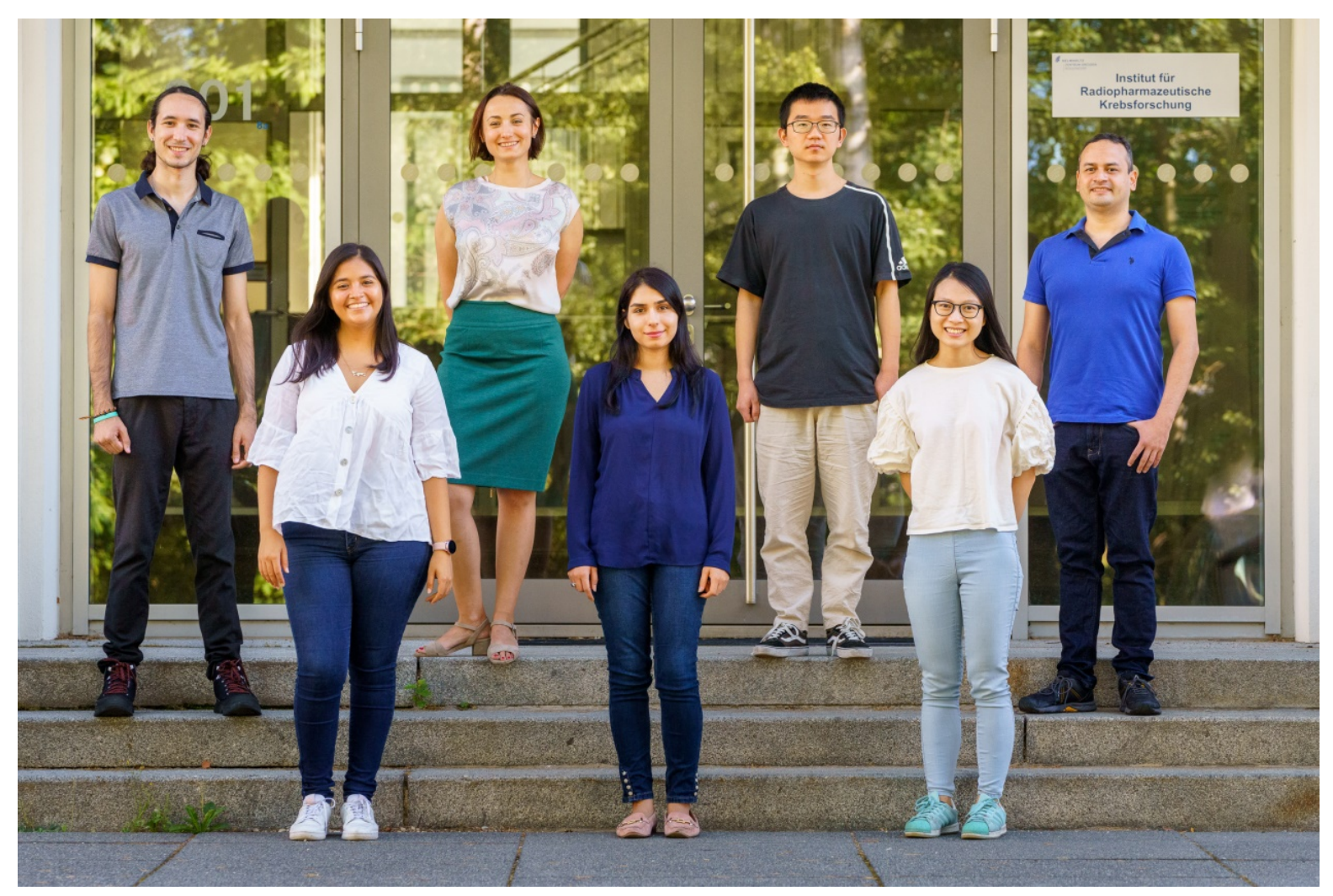




\section{Thanks for your attention!}
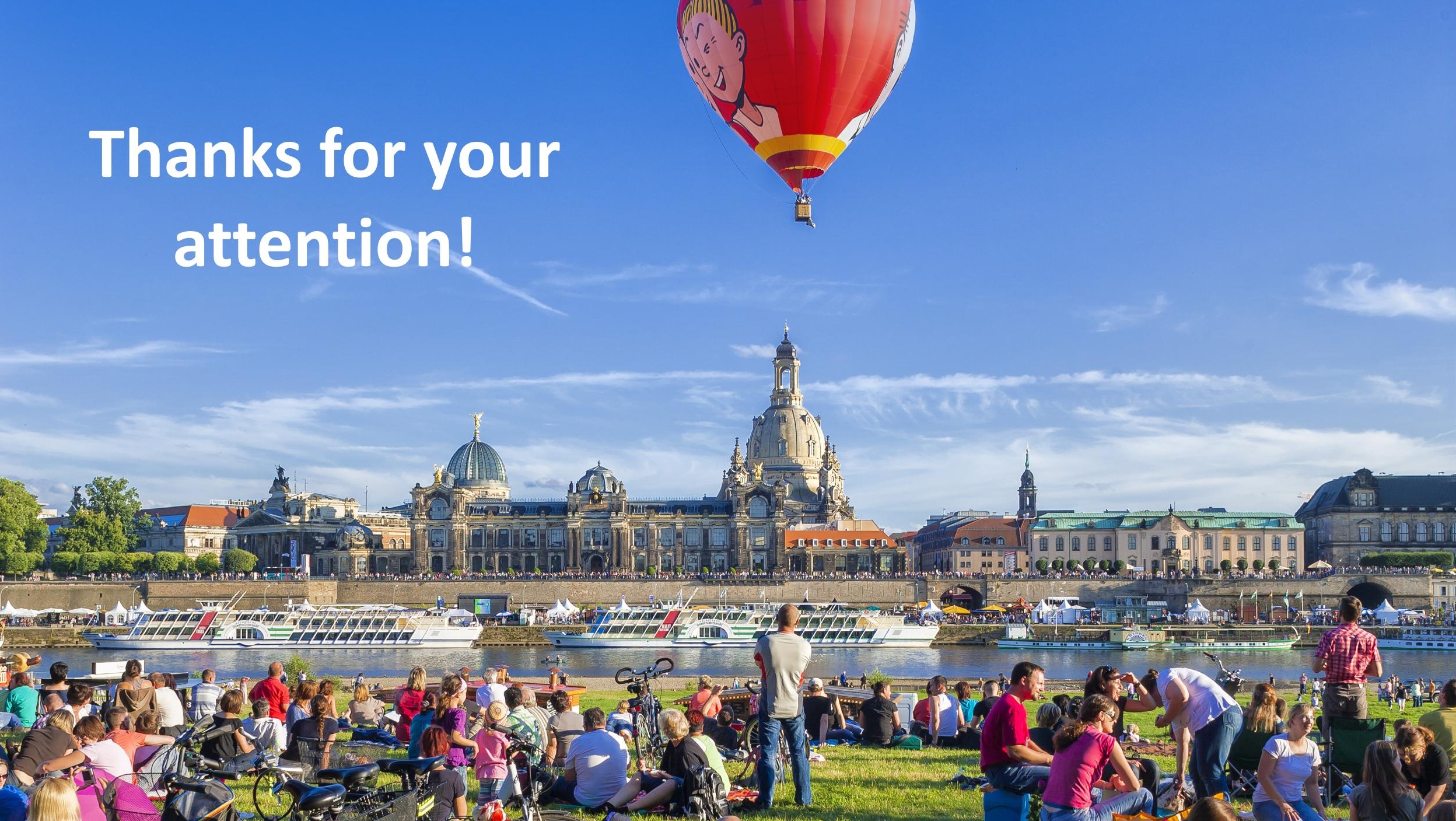